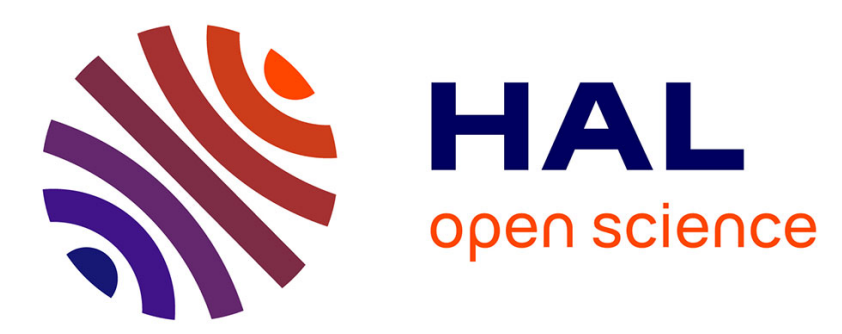

\title{
Stress-dilatancy behavior for sand under loading and unloading conditions
}

\author{
Zhenyu Yin, Ching S. Chang
}

\section{To cite this version:}

Zhenyu Yin, Ching S. Chang. Stress-dilatancy behavior for sand under loading and unloading conditions. International Journal for Numerical and Analytical Methods in Geomechanics, 2013, 37 (8), pp.855-870. 10.1002/nag.1125 . hal-01007331

\section{HAL Id: hal-01007331 \\ https://hal.science/hal-01007331}

Submitted on 10 Mar 2018

HAL is a multi-disciplinary open access archive for the deposit and dissemination of scientific research documents, whether they are published or not. The documents may come from teaching and research institutions in France or abroad, or from public or private research centers.
L'archive ouverte pluridisciplinaire HAL, est destinée au dépôt et à la diffusion de documents scientifiques de niveau recherche, publiés ou non, émanant des établissements d'enseignement et de recherche français ou étrangers, des laboratoires publics ou privés. 


\title{
Stress-dilatancy behavior for sand under loading and unloading conditions
}

\author{
Zhen-Yu Yin ${ }^{1, *, \dagger}$ and Ching S. Chang ${ }^{2}$ \\ ${ }^{1}$ Department of Civil Engineering, Shanghai Jiao Tong University, Shanghai, 200240, China \\ ${ }^{2}$ Department of Civil and Environmental Engineering, University of Massachusetts, Amherst, MA 01002, USA
}

Experimental results have shown very different stress-dilatancy behavior for sand under loading and unloading conditions. Experimental results have also shown significant effects of inherent anisotropy. In this article, a micromechanics-based method is presented, by which the stress-dilatancy relation is obtained through the consideration of slips at the interparticle contacts in all orientations. The method also accounts for the effect of inherent anisotropy in sand. Experimental results on Toyoura sand and Hostun sand are used for illustration of the proposed method.

KEY WORDS: $\quad$ sand; micromechanics; plasticity; dilatancy; anisotropy; unloading

\section{INTRODUCTION}

Stress-dilatancy behavior is an important issue in soil mechanics. Rowe [1] and Roscoe et al. [2] introduced two different forms of stress-dilatancy equations for sand, which have been widely used as flow rules in elastoplasticity models for sand. Until today, most plasticity models are either based on Roscoe's or Rowe's dilatancy equations, for example, Nova [3], Jefferies [4], Manzari and Dafalias [5], Gajo and Muir Wood [6], Li et al. [7], Wan and Guo [8], and Anandarajah [9], among others.

Experimental results have shown that the dilatancy behavior is very different for loading and unloading conditions. Thus, two equations of different forms are often required separately such as that discussed by Pradhan and Tatsuoka [10] and Jefferies [4]. Furthermore, the experimental results show a wide range of dilatancy behaviors for different types of sand, which is attributed to the various fabric structures of sands due to particle shapes and deposition processes. However, very few dilatancy models have considered the effect of fabric structure. A model worth noted is proposed by Wan and Guo [8], which considered a fabric tensor. Nevertheless, most models for soil dilatancy, including that by Wan and Guo [8], are in themselves a macroscale abstraction of the underlying micromechanical reality; they do not explicitly model the grain realignments and grain slips.

Along this line of thinking, we propose to model the stress-dilatancy behavior using a micromechanics approach in which slip mechanism is considered for the dilatancy behavior between two particles. Because of the difference in slip patterns for loading and unloading conditions, the derived dilatancy behaviors, naturally, will be different.

In what follows, the stress-dilatancy relations under different loading conditions are first examined on the basis of several experimental results available in the literature, followed by an overview of the

\footnotetext{
*Correspondence to: Zhen-Yu Yin, Department of Civil Engineering, Shanghai Jiao Tong University, Shanghai, 200240, China.

†E-mail: zhenyu.yin@gmail.com
} 
Roscoe's and Rowe's equations. After that, the slip mechanism is discussed for loading and unloading conditions. The slip mechanism is implemented in the micromechanics approach proposed by Chang and Hicher [11], which determines the overall deformation by considering slip mechanism at interparticle contacts in all orientations. Experimental results on Toyoura sand are used for evaluating the model's capability for prediction of dilatancy behavior in both loading and unloading conditions. The local dilatancy relations at interparticle planes due to applied load are also discussed.

\section{OVERVIEW OF STRESS-DILATANCY BEHAVIOR}

\subsection{Stress-dilatancy equations}

Dilatancy models usually start from a proposition as to the way in which plastic work is dissipated, Taylor's [12] analysis of direct shear box test of sand assumed that the entire input work is dissipated in friction. This principle of energy dissipation has been extended for the condition of triaxial tests by Roscoe et al. [2], given by

$$
p^{\prime} d \varepsilon_{\mathrm{v}}^{\mathrm{p}}+q d \varepsilon_{\mathrm{d}}^{\mathrm{p}}=M p^{\prime} d \varepsilon_{\mathrm{d}}^{\mathrm{p}} \quad \text { for loading; } p^{\prime} d \varepsilon_{\mathrm{v}}^{\mathrm{p}}+q d \varepsilon_{\mathrm{d}}^{\mathrm{p}}=-M p^{\prime} d \varepsilon_{\mathrm{d}}^{\mathrm{p}} \quad \text { for unloading }
$$

where $p^{\prime}=\left(\sigma_{\mathrm{a}}^{\prime}+2 \sigma_{\mathrm{r}}^{\prime}\right) / 3$ is the mean effective stress, $q=\sigma_{\mathrm{a}}^{\prime}-\sigma_{\mathrm{r}}^{\prime}$ is the deviatoric stress, and $d \varepsilon_{\mathrm{v}}^{\mathrm{p}}=$ $d \varepsilon_{\mathrm{a}}^{\mathrm{p}}+2 d \varepsilon_{\mathrm{r}}^{\mathrm{p}}$ is the volumetric strain increment. The superscript $\mathrm{p}$ denotes plastic components, the deviatoric strain increment $d \varepsilon_{\mathrm{d}}^{\mathrm{p}}=2\left(d \varepsilon_{\mathrm{a}}^{\mathrm{p}}-d \varepsilon_{\mathrm{r}}^{\mathrm{p}}\right) / 3$, and the subscripts a and $\mathrm{r}$ indicate axial and radial directions, respectively, in a triaxial setup. $M$ is the slope of critical state line.

The right-hand term of Equation (1) represents the dissipation energy in friction, which must be positive in either loading or unloading tests. Note that the value of $d \varepsilon_{\mathrm{d}}^{\mathrm{p}}$ is positive in loading and negative in unloading condition. Equation (1) can be rearranged to the form of dilatancy equation

$$
\frac{d \varepsilon_{\mathrm{v}}^{\mathrm{p}}}{d \varepsilon_{\mathrm{d}}^{\mathrm{p}}}=M_{\mathrm{c}}-\frac{q}{p^{\prime}} \quad \text { for loading; } \quad \frac{d \varepsilon_{\mathrm{v}}^{\mathrm{p}}}{d \varepsilon_{\mathrm{d}}^{\mathrm{p}}}=-M_{\mathrm{e}}-\frac{q}{p^{\prime}} \quad \text { for unloading }
$$

where $M_{\mathrm{c}}=6 \sin \phi_{0} /\left(3-\sin \phi_{0}\right)$ and $M_{\mathrm{e}}=6 \sin \phi_{0} /\left(3+\sin \phi_{0}\right)$ are the stress ratio corresponding to zero dilatancy for loading and unloading, respectively, which is also termed as the slope of phase transformation line [13] or characteristic line [14]. The parameter $\phi_{0}$ is termed as the phase transformation angle.

Rowe $[1,15]$ assumed that the ratio of the input energy increment to the output energy increment is a constant, denoted as $K$. In a loading test, the input energy increment is $\sigma_{\mathrm{a}}^{\prime} d \varepsilon_{\mathrm{a}}^{\mathrm{p}}$ and the output energy increment is $2 \sigma_{\mathrm{r}}^{\prime} d \varepsilon_{\mathrm{r}}^{\mathrm{p}}$, and vice versa for an unloading test. Hence,

$$
\frac{\sigma^{\prime}{ }_{\mathrm{a}}}{\sigma_{\mathrm{r}}^{\prime}}=K\left(1-\frac{d \varepsilon_{\mathrm{v}}^{\mathrm{p}}}{d \varepsilon_{\mathrm{a}}^{\mathrm{p}}}\right) \quad \text { for loading; } \quad \frac{\sigma_{\mathrm{r}}^{\prime}}{\sigma_{\mathrm{a}}^{\prime}}=\frac{1}{K}\left(1-\frac{d \varepsilon_{\mathrm{v}}^{\mathrm{p}}}{d \varepsilon_{\mathrm{a}}^{\mathrm{p}}}\right) \quad \text { for unloading }
$$

Because of the variation of experimental tests, a constant $D$ is often introduced in Equation (2), such as that proposed by Nova [3], Jefferies [4], Gajo and Muir Wood [6], Li et al. [7], and Anandarajah [9]:

$$
\frac{d \varepsilon_{\mathrm{v}}^{\mathrm{p}}}{d \varepsilon_{\mathrm{d}}^{\mathrm{p}}}=D\left(M_{\mathrm{c}}-\frac{q}{p^{\prime}}\right) \quad \text { for loading; } \quad \frac{d \varepsilon_{\mathrm{v}}^{\mathrm{p}}}{d \varepsilon_{\mathrm{d}}^{\mathrm{p}}}=D\left(-M_{\mathrm{e}}-\frac{q}{p^{\prime}}\right) \quad \text { for unloading }
$$

The value of $D$ is different for loading and unloading case. It has also been suggested that the value of $M$ is a function of density state (e.g. Manzari and Dafalias [5]). 


\subsection{Experimental measurements}

Figure 1 shows the stress-dilatancy behavior for three different types of sands: Toyoura sand [16], Erksak Sand [17], and Portaway Sand [18], where $d_{0}$ is defined as the $d \varepsilon_{\mathrm{v}}^{\mathrm{p}} / d \varepsilon_{\mathrm{d}}^{\mathrm{p}}$ at $q=0$. The dilatancy behavior is plotted in a plane of $d \varepsilon_{\mathrm{v}}^{\mathrm{p}} / d \varepsilon_{\mathrm{d}}^{\mathrm{p}}$ versus $q / p^{\prime}$ for both loading and unloading conditions. The sign of $d \varepsilon_{\mathrm{v}}^{\mathrm{p}}$ is positive for contraction and negative for dilation. In the unloading condition, both $d \varepsilon_{\mathrm{d}}^{\mathrm{p}}$ and $q$ are negative.

In Figure 1, two intersection points along the $q / p^{\prime}$ axis are termed $M_{c}$ and $M_{e}$, respectively, for loading and unloading conditions. The other two intersection points along the $d \varepsilon_{\mathrm{v}}^{\mathrm{p}} / d \varepsilon_{\mathrm{d}}^{\mathrm{p}}$ axis are termed $d_{c}$ and $d_{e}$. The slopes of the two lines are marked as $D$ in Figure 1.

A comparison is made in Figure 2 between the dilatancy equations (by Roscoe and Rowe) and the experimental results for the three sands. According to Roscoe's dilatancy equation, the dilatancy curves are linear lines, with the value of $d_{\mathrm{c}}=M_{\mathrm{c}}$ and $d_{\mathrm{e}}=M_{\mathrm{e}}$. Thus, the slopes for both loading and unloading conditions are $D_{\mathrm{c}}=D_{\mathrm{e}}=-1$. Using Rowe's equation, the dilatancy curves are slightly nonlinear. The value of $d_{\mathrm{c}}$ is smaller than that of Roscoe's equation in loading, and the value of $d_{\mathrm{c}}$ is greater in unloading (based on Equation (3) with $\sigma_{\mathrm{a}}^{\prime}=\sigma_{\mathrm{r}}^{\prime}$ ).

Because of the large range of dilatancy behavior (see Figure 1), both Roscoe's and Rowe's equations are not able to fit various patterns of measured behavior.
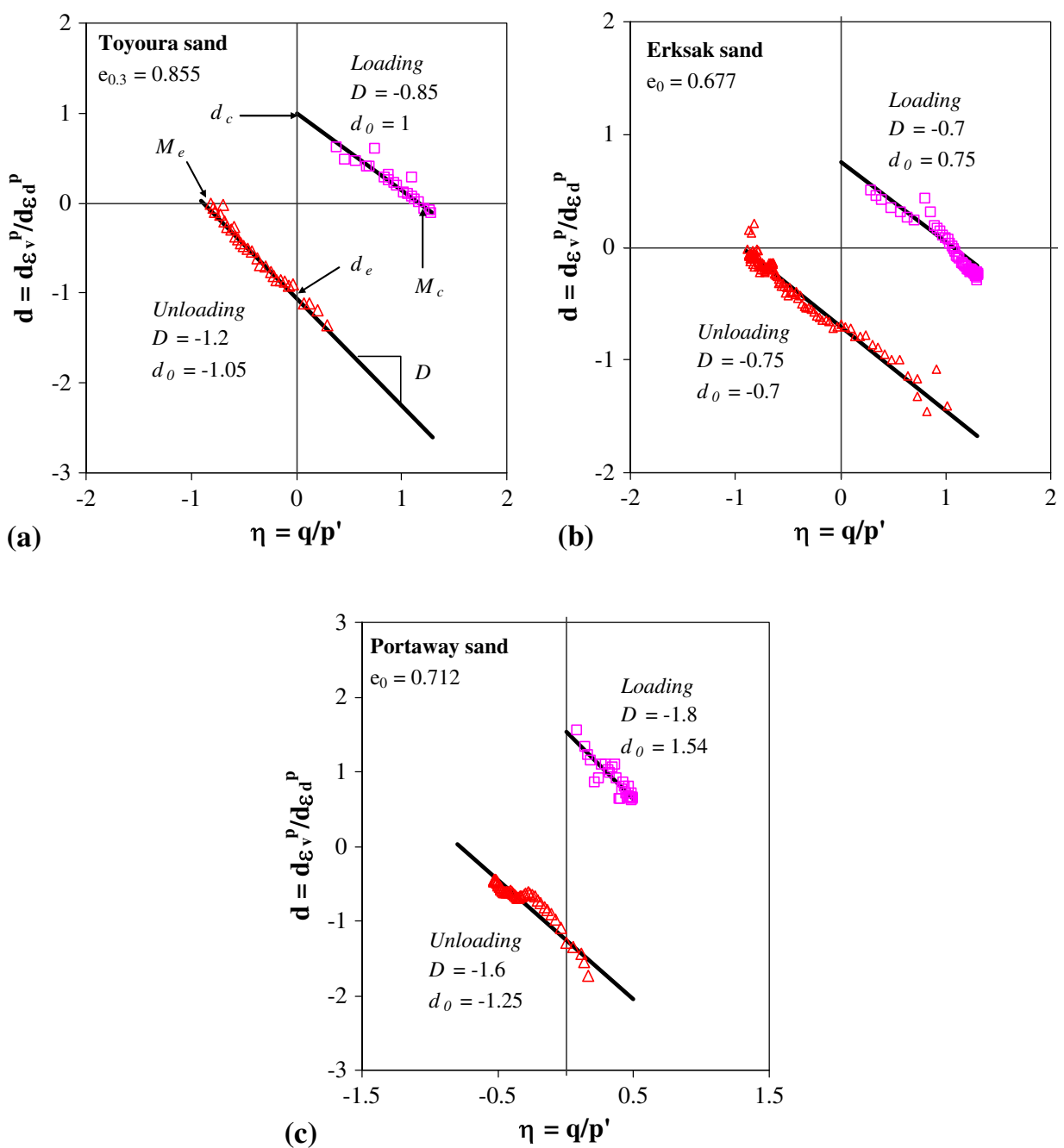

Figure 1. Stress-dilatancy relations under different loading conditions for different sands. 

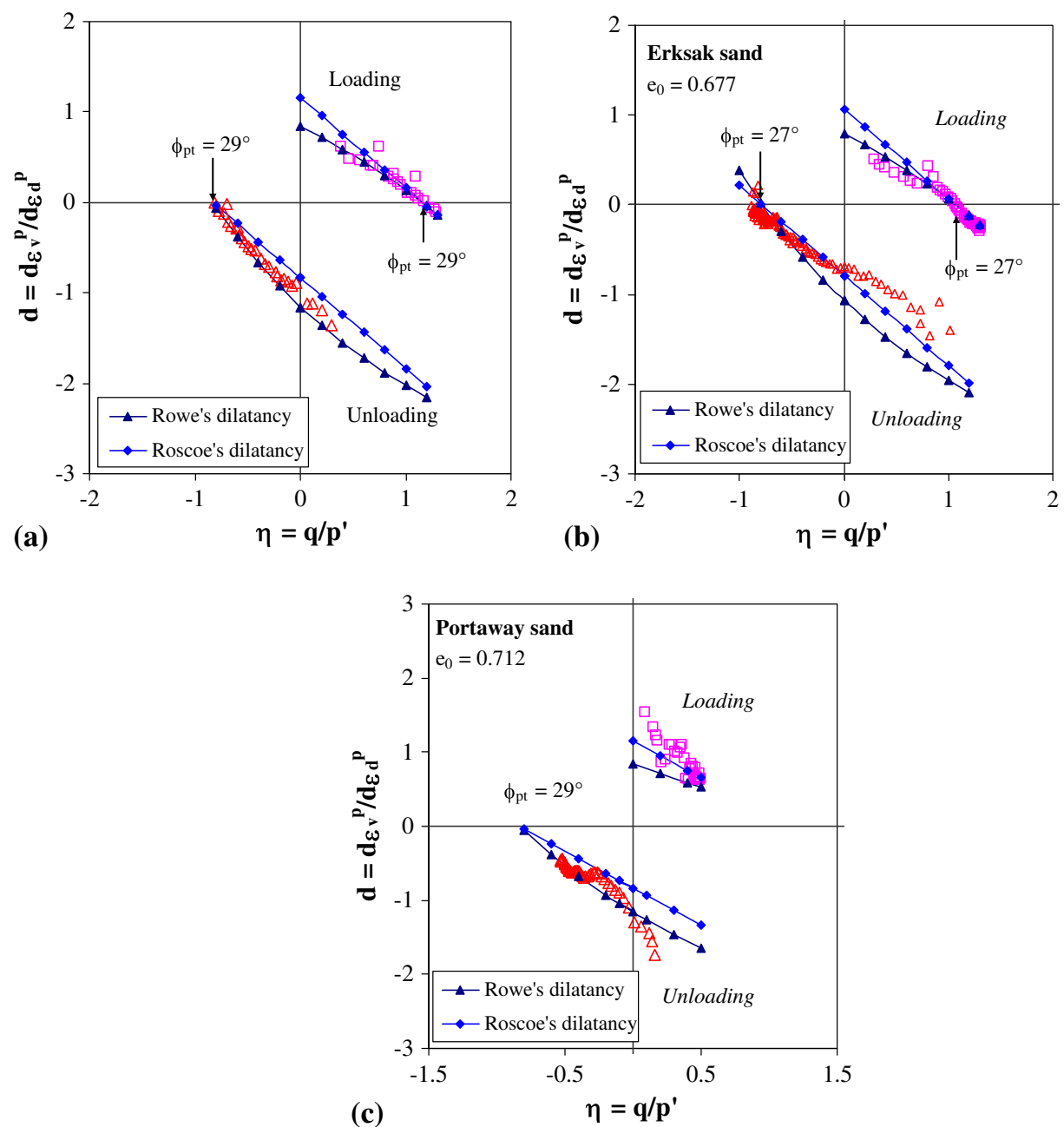

Figure 2. Stress-dilatancy relations obtained from different dilatancy equations.

\subsection{A micromechanical approach}

In this article, a micromechanics approach is adopted for modelling the plastic flow of sand. The approach, using a direct way to simulate the underlying physical processes of deformation, is expected to predict correctly the dilatancy relationship for both loading and unloading conditions. Also, the approach can easily represent inherent anisotropy of packing structure. For this purpose, the micromechanics approach by Chang and Hicher [11] is selected for this study.

\section{MICROMECHANICS-BASED MODEL}

\subsection{Brief description}

In this micromechanics approach, the deformation of an assembly can be obtained by integrating the movement of the interparticle contacts in all orientations. The orientation-dependent properties of soil can be explicitly represented as inherent anisotropy. The model is limited to narrowly graded sands. The brief description for the model by Chang and Hicher [11] can be found in Appendix A, which includes the definitions of symbols used in this section. The treatment of dilatancy behavior at the interparticle level for unloading condition is discussed in the next section. 


\subsection{Dilatancy behavior of two particles}

3.2.1. Slip mechanism for loading and unloading conditions. Sliding between two particles is governed by the interparticle friction angle (assumed to be $\phi_{\mu}$ ). For a pair of particles with a contact force $F$, the angle of obliquity is also termed as the mobilized angle $\phi_{\mathrm{m}}$, which is the angle between the contact normal and the vector $\mathbf{F}$ as illustrated as Figure 3(a) (i.e. $\tan \phi_{\mathrm{m}}=f_{\mathrm{r}} / f_{\mathrm{n}}$, see Appendix A). Under a loading condition, the mobilized angle $\phi_{\mathrm{m}}$ increases and the preferred sliding direction is in the direction of B (see Figure 3(a)). On the other hand, under an unloading condition, the mobilized angle $\phi_{\mathrm{m}}$ decreases, and the preferred sliding direction is on the opposite side, along the direction of $\mathrm{A}$.

The sliding direction for loading (Figure 3(b)) and unloading (Figure 3(c)) gives the following equations:

$$
\frac{d \delta_{\mathrm{n}}}{d \delta_{\mathrm{r}}}=\tan \left(\phi_{\mu}-\phi_{\mathrm{m}}\right) \quad \text { for loading; } \quad \frac{d \delta_{\mathrm{n}}}{d \delta_{\mathrm{r}}}=\tan \left(\phi_{\mu}+\phi_{\mathrm{m}}\right) \quad \text { for unloading }
$$

Another way to derive the slip direction is to use a preposition that the input plastic work is dissipated in friction, as used in the model by Chang and Hicher [11]. Assuming that the plastic work for a contact plane due to both normal and shear movements $\left(f_{\mathrm{n}} d \delta_{\mathrm{n}}^{\mathrm{p}}+f_{\mathrm{r}} d \delta_{\mathrm{r}}^{\mathrm{p}}\right)$ is equal to the energy loss due to friction $\left(f_{\mathrm{n}} \tan \phi_{0} d \delta_{\mathrm{r}}^{\mathrm{p}}\right)$ at the contact, the local dilatancy can be derived as follows:

$$
\frac{d \delta_{\mathrm{n}}^{\mathrm{p}}}{d \delta_{\mathrm{r}}^{\mathrm{p}}}=\tan \phi_{\mu}-\tan \phi_{\mathrm{m}}
$$

Considering the sliding effect for unloading, the dilatancy equation becomes

$$
\frac{d \delta_{\mathrm{n}}^{\mathrm{p}}}{d \delta_{\mathrm{r}}^{\mathrm{p}}}=-\tan \phi_{\mu}-\tan \phi_{\mathrm{m}}
$$

It is noted that Equations (6) and (7) are similar to that given in Equation (5).

3.2.2. Plastic sliding model on an interparticle contact. The yield function $F$ is assumed to be of Mohr-Coulomb type, defined in a contact-force space (e.g. $f_{\mathrm{n}}, f_{\mathrm{s}}$, and $f_{\mathrm{t}}$, see coordinate system in Figure 4).

$$
F=\frac{f_{\mathrm{r}}}{f_{\mathrm{n}}}-\kappa
$$

where the shear force $f_{\mathrm{r}}$ can be defined as $f_{\mathrm{r}}=\sqrt{f_{\mathrm{s}}^{2}+f_{\mathrm{t}}^{2}} \cdot \kappa$ is a hardening function, expressed by

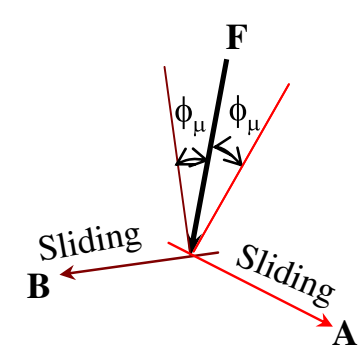

(a)

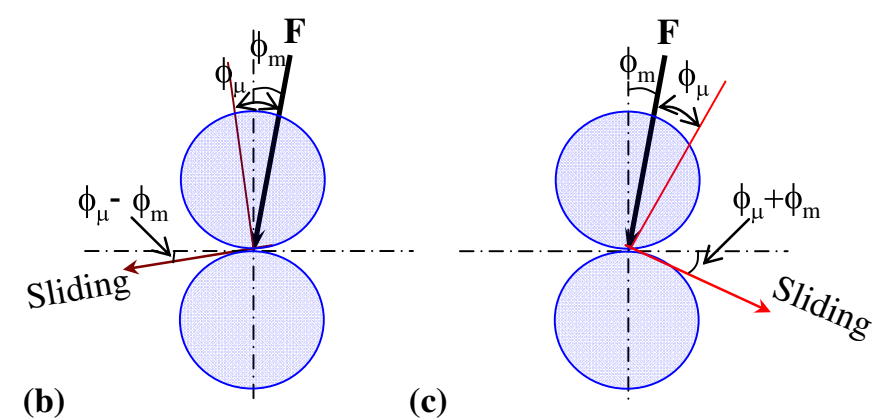

(c)

Figure 3. Illustration of slip directions under loading and unloading conditions. 

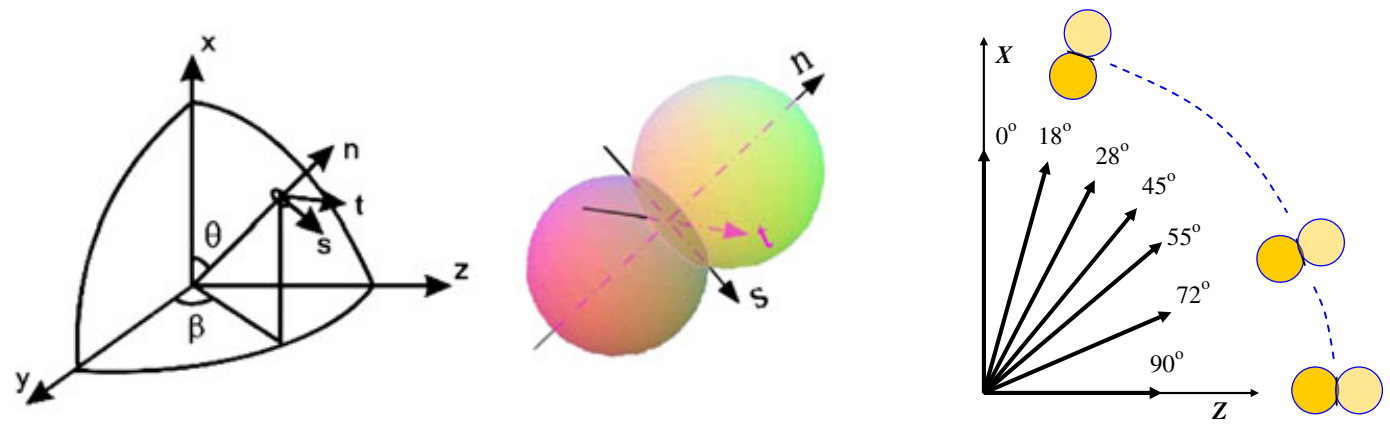

Figure 4. Local coordinate at interparticle contact.

$$
\kappa=\frac{k_{\mathrm{p} 0} \tan \phi_{\mathrm{p}} \delta_{\mathrm{r}}^{\mathrm{p}}}{\tan \phi_{\mathrm{p}}+k_{\mathrm{p} 0} \delta_{\mathrm{r}}^{\mathrm{p}}}
$$

where the plastic sliding defined as $\delta_{\mathrm{r}}^{\mathrm{p}}=\sqrt{\left(\delta_{\mathrm{s}}^{\mathrm{p}}\right)^{2}+\left(\delta_{\mathrm{t}}^{\mathrm{p}}\right)^{2}}$.

Upon shear reversal, the direction of sliding on each interparticle plane is reversed. At the moment of shear reversal, the plastic displacements $\delta_{\mathrm{s}}^{\mathrm{pR}}$ and $\delta_{\mathrm{t}}^{\mathrm{pR}}$ and the forces $f_{\mathrm{n}}^{\mathrm{R}}, f_{\mathrm{s}}^{\mathrm{R}}$, and $f_{\mathrm{t}}^{\mathrm{R}}$ are regarded as residual state variables of the contacts. The residual state has a significant influence on the subsequent sliding behavior. Thus, we take account of the residual state variables in the hardening equation as follows:

$$
\kappa=\frac{k_{\mathrm{p} 0} \tan \phi_{\mathrm{p}}^{*} \delta_{\mathrm{r}}^{\mathrm{p} *}}{\tan \phi_{\mathrm{p}}^{*}+k_{\mathrm{p} 0} \delta_{\mathrm{r}}^{\mathrm{p} *}}
$$

Note that these two equations carry the same form as the equation for loading condition. The superscript asterisk $\left(^{*}\right)$ represents the effect of residual state on the plastic shear displacement $\delta_{\mathrm{r}}^{\mathrm{p} *}$, and on the peak friction angle $\phi_{\mathrm{p}}^{*}$, which are defined as follows:

$$
\begin{gathered}
\delta_{\mathrm{r}}^{\mathrm{p} *}=\sqrt{\left(\delta_{\mathrm{s}}^{\mathrm{p}}-\delta_{\mathrm{s}}^{\mathrm{pR}}\right)^{2}+\left(\delta_{\mathrm{t}}^{\mathrm{p}}-\delta_{\mathrm{t}}^{\mathrm{pR}}\right)^{2}} \\
\tan \phi_{\mathrm{p}}^{*}=\sqrt{\left(m_{\mathrm{s}} \tan \phi_{\mathrm{p}}-\frac{f_{\mathrm{s}}^{\mathrm{R}}}{f_{\mathrm{n}}^{\mathrm{R}}}\right)^{2}+\left(m_{\mathrm{t}} \tan \phi_{\mathrm{p}}-\frac{f_{\mathrm{t}}^{\mathrm{R}}}{f_{\mathrm{n}}^{\mathrm{R}}}\right)^{2}}
\end{gathered}
$$

where $m_{\mathrm{s}}$ and $m_{\mathrm{t}}$ are given by

$$
m_{\mathrm{s}}=\frac{r_{\mathrm{s}}^{*}}{\sqrt{\left(r_{\mathrm{s}}^{*}\right)^{2}+\left(r_{\mathrm{t}}^{*}\right)^{2}}} ; \quad m_{\mathrm{t}}=\frac{r_{\mathrm{t}}^{*}}{\sqrt{\left(r_{\mathrm{s}}^{*}\right)^{2}+\left(r_{\mathrm{t}}^{*}\right)^{2}}}
$$

The mobilized force ratios $r_{\mathrm{s}}^{*}$ and $r_{\mathrm{t}}^{*}$, influenced by the residual state variables, are defined as

$$
r_{\mathrm{s}}^{*}=\left(\frac{f_{\mathrm{s}}}{f_{\mathrm{n}}}\right)^{*}=\frac{f_{\mathrm{s}}}{f_{\mathrm{n}}}-\frac{f_{\mathrm{s}}^{\mathrm{R}}}{f_{\mathrm{n}}^{\mathrm{R}}} ; \quad r_{\mathrm{t}}^{*}=\left(\frac{f_{\mathrm{t}}}{f_{\mathrm{n}}}\right)^{*}=\frac{f_{\mathrm{t}}}{f_{\mathrm{n}}}-\frac{f_{\mathrm{t}}^{\mathrm{R}}}{f_{\mathrm{n}}^{\mathrm{R}}}
$$

A schematic explanation of the effects of reverse state is shown in Figure 5. When the residual state is null, all previously mentioned equations return to the usual conditions for monotonic loading. 


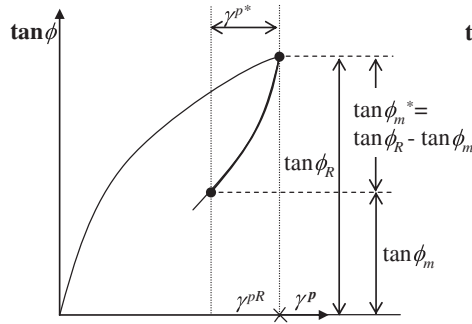

(a)

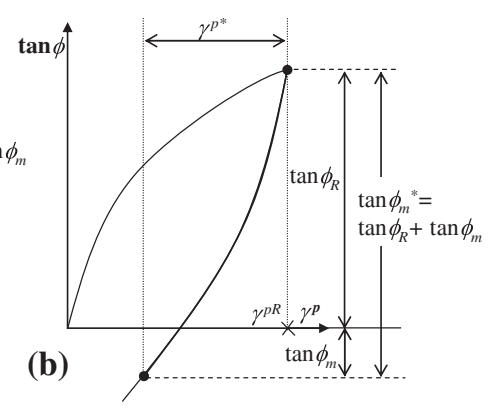

(c)

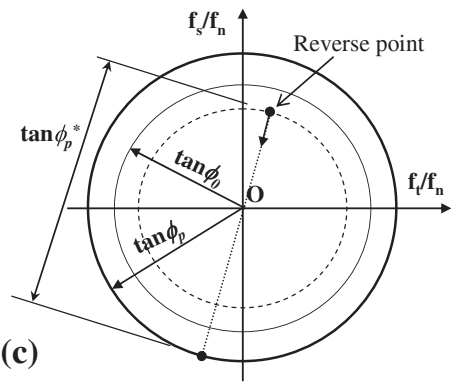

Figure 5. Principle of the force reversal.

The flow rule considering sliding directions modified from Equations (6) and (7) is given as

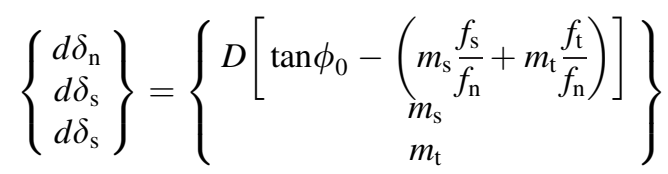

Equation (15) can be reduced to Equation (6) for loading and to Equation (7) for unloading, which gives different amount of dilatancy upon shear reversal. This flow rule represents the slip mechanism described in the previous section.

To account for the interactions among neighboring particles, we introduced a density state $\psi=e_{\mathrm{c}} / e$ in reference to the void ratio at critical state. The void ratio corresponding to this state is $e_{\mathrm{c}}$. The critical state line can be expressed as follows for sand:

$$
e_{\mathrm{c}}=e_{\mathrm{ref}}-\lambda\left(\frac{p^{\prime}}{p_{\text {at }}}\right)^{\xi}
$$

where $\xi$ and $\mid$ are two material constants, and $p^{\prime}$ is the mean effective stress of the packing.

Resistance against sliding on a contact plane is dependent on the degree of interlocking by neighboring particles. The resistance can be related to the state of packing void ratio $e$ by (Biarez and Hicher [19]):

$$
\tan \phi_{\mathrm{p}}=\left(\frac{e_{\mathrm{c}}}{e}\right)^{m} \tan \phi_{\mu}
$$

where $m$ is a material constant (Biarez and Hicher [19]), which is typically equal to 1 .

The elastic behavior on a contact plane can be found in Appendix A. The stress-strain relationship of an assembly can be determined from integrating the behavior of interparticle contacts in all orientations (see Appendix A).

\section{EVALUATION OF THE MICROMECHANICS-BASED METHOD}

In this section, Toyoura sand in drained loading unloading condition is used for evaluating the model applicability. Very loose Hostun sand in undrained condition is also used.

\subsection{Stress-dilatancy behavior of Toyoura sand}

The experimental results on Toyoura sand is used for investigating the stress-dilatancy relations under both loading and unloading conditions. The selected drained triaxial tests were performed by Pradhan et al. [16] under a constant $p^{\prime}$ of $98 \mathrm{kPa}$ on Toyoura sand $\left(e_{0.3}=0.855\right.$ representing the void ratio under $p^{\prime}=0.3 \mathrm{kgf} / \mathrm{cm}^{2}$ ), which has a maximum void ratio of 0.977 , a minimum void ratio of 0.597 , 
and a specific gravity of 2.65 . The mean size of the particle for the sand is $d=0.17 \mathrm{~mm}$. The interparticle elastic constant $k_{n 0}$ is obtained to be $12.5 \mathrm{~N} / \mathrm{mm}$ and $n=0.5$ from isotropic compression test (see Figure 7(a)). The internal friction angle $\phi_{\mu}=31^{\circ}$ is obtained from triaxial tests. The parameters for critical state line are obtained from test results by Verdugo and Ishihara [20]: $e_{\text {ref }}=0.934, \lambda=0.019$, and $\xi=0.7$ (see Figure 6(a)). The parameter for plastic modulus $k_{\mathrm{pR}}=0.15$ is obtained from fitting the stress strain curve (Figure 6(b)). The parameter for shear elastic modulus $k_{\mathrm{rR}}=0.5$ is assumed. All selected values of parameters are summarized in Table I.

As discussed earlier, the different patterns of behaviors for the two types of sand are caused by the inherent packing structure of sand. To analyze the effect of packing structural anisotropy, we made the dilatancy constant $D$ to be orientation dependent, such that the slip dilatancy is different for contacts. For the cross anisotropy of dilatancy constant $D$ with three different values in principal axes $D_{11}, D_{22}$, and $D_{33}$, a second-order tensor form can be written as

$$
[D]=\left[\begin{array}{ccc}
D_{11} & 0 & 0 \\
0 & D_{22} & 0 \\
0 & 0 & D_{33}
\end{array}\right]=D_{\text {ave }}\left[\begin{array}{ccc}
1+a_{0} & 0 & 0 \\
0 & 1-\frac{a_{0}}{2} & 0 \\
0 & 0 & 1-\frac{a_{0}}{2}
\end{array}\right]
$$

where $D_{\text {ave }}=\left(D_{11}+D_{22}+D_{33}\right) / 3$. The orientation distribution of the normal elastic stiffness for a crossanisotropic case is (Chang and Misra [21])

$$
D(\theta)=D_{\text {ave }}\left(1+\frac{a_{0}}{4}(3 \cos 2 \theta+1)\right)
$$

where the angle $\theta$ is defined in Figure 4 in a spherical coordinate. In this cross-anisotropic case, the orientation distribution is symmetrical about its major axis that coincides with $x$-direction (the vertical direction).

Using the Toyoura sand with all the parameters in Table I, three cases with different degrees of anisotropy are considered $\left(a_{0}=-0.8,0\right.$, and 1$)$. The three-dimensional pictures for the orientationdependent dilatancy constant are shown in Figures 7(a)-7(c). The distribution in the $x-z$ plane is shown in Figure 7(d).

Figures 8(a)-8(b) show the effect of the three anisotropic constants on the dilatancy and volume change behavior under $D_{\text {ave }}=0.7$. On the dilatancy behavior in Figure 8(a), the anisotropy assumption has shown effect on the dilatancy curves for loading test and unloading test. Figure 8(b)
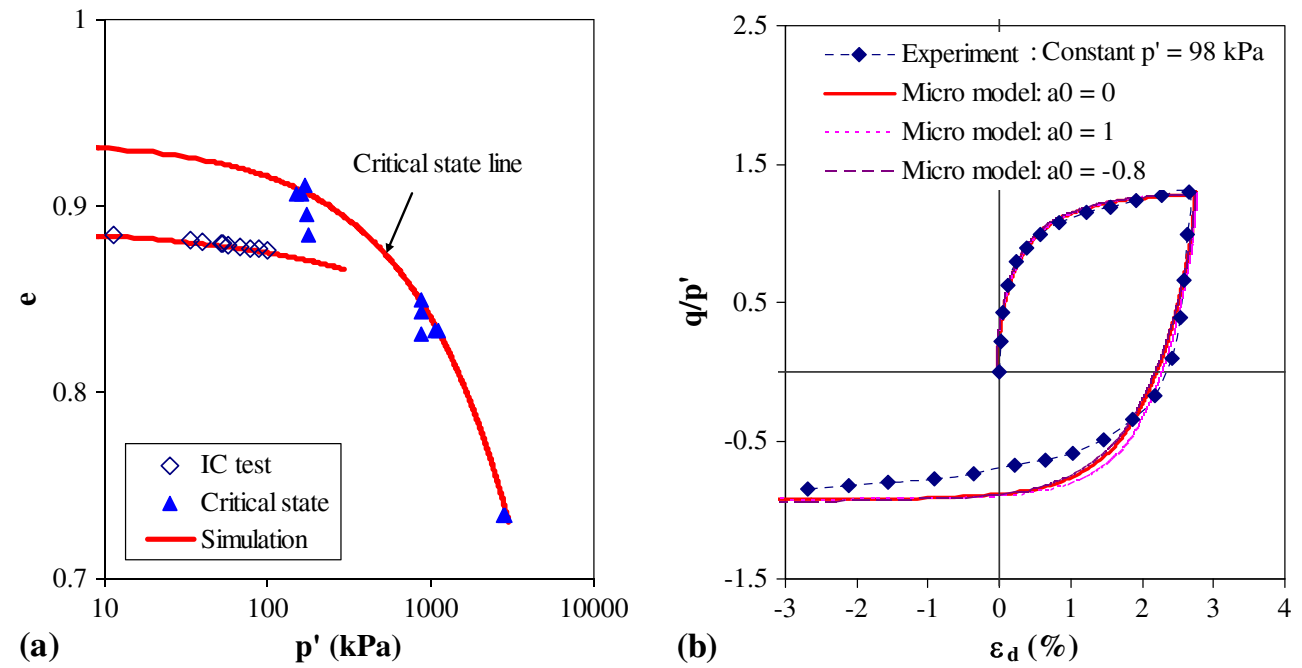

Figure 6. Experimental results on Toyoura sand: (a) isotropic compression curve and critical states, (b) constant $p^{\prime}$ test under drained triaxial condition with loading and unloading stages. 
Table I. Values of parameters for very loose Hostun sand and Toyoura sand.

\begin{tabular}{|c|c|c|c|c|c|c|c|c|c|c|}
\hline \multirow[b]{2}{*}{ Parameters } & \multicolumn{3}{|c|}{ Global parameters } & \multicolumn{7}{|c|}{ Interparticle parameters } \\
\hline & $\lambda$ & $e_{\text {ref }}$ & $\xi$ & $D$ & $\phi_{\mu}^{\prime}$ & $\phi_{0}$ & $n$ & $k_{\mathrm{n} 0}(\mathrm{~N} / \mathrm{mm})$ & $k_{\mathrm{rR}}$ & $k_{\mathrm{pR}}$ \\
\hline Toyoura sand & 0.019 & 0.934 & 0.7 & $0.7^{\mathrm{a}}$ & $31^{\circ}$ & $29^{\circ}$ & 0.5 & 12.5 & 0.5 & 0.15 \\
\hline Hostun sand & 0.35 & 1.18 & 0.1 & $3^{\mathrm{a}}$ & $33^{\circ}$ & $33^{\circ}$ & 0.5 & 6.2 & 0.5 & 1.0 \\
\hline
\end{tabular}

${ }^{\mathrm{a}}$ Average value.

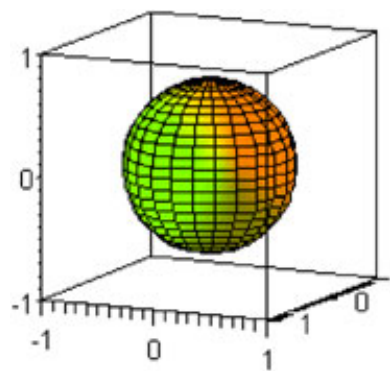

(a) $\mathrm{D}_{\mathrm{ave}}=0.7, \mathrm{a}_{0}=0$

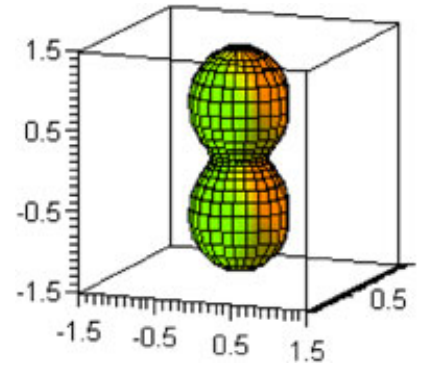

(c) $\mathrm{D}_{\text {ave }}=0.7, \mathrm{a}_{0}=1$

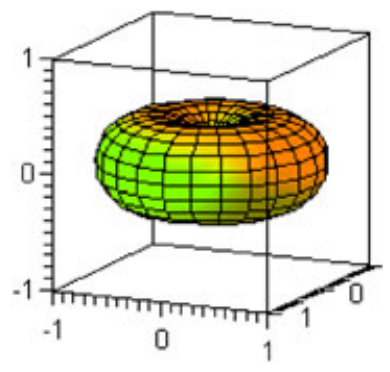

(b) $\mathrm{D}_{\text {ave }}=0.7, \mathrm{a}_{0}=-0.8$

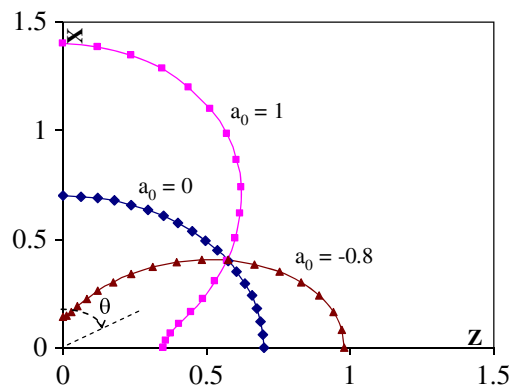

(d)

Figure 7. Schematic plot for orientation distribution of inherited anisotropy of dilatancy constant in sphere coordinate.

shows that the volume change behavior for loading test is slightly influenced by anisotropy, but significant effects can be seen on the volume change behavior during unloading.

It is noted that there are many combinations of parameters $D_{\text {ave }}$ and $a_{0}$, which can equally fit well the loading curve (such as $a_{0}=-0.8, D_{\text {ave }}=0.65 ; a_{0}=0, D_{\text {ave }}=0.7$; and $a_{0}=1, D_{\text {ave }}=0.75$ ) as shown in Figure 8(c). Therefore, to determine the two parameters, the unloading curve should be also used. As indicated in Figure 8(c), only one set of parameters $\left(a_{0}=0, D_{\text {ave }}=0.7\right)$ can fit well both loading and unloading curves. The three sets of parameters also display significant difference on the volume change behavior for unloading condition (see Figure 8(d)).

The stress-dilatancy behavior predicted by the present model is based on mobilization of contact planes. Therefore, it is of interest to observe the predicted local dilatancy behavior on individual contact planes. In a triaxial tests, the applied loading is axisymmetric about vertical $x$-axis; thus, the orientation of a given contact plane can be represented by an inclined angle, $\theta$, which is measured between the branch vector and the $x$-axis of the coordinate system as shown in Figure $4\left(\theta=0^{\circ}\right.$ corresponds to a horizontal contact plane). Seven contact planes were selected for this investigation: $\theta=0^{\circ}, 18^{\circ}, 28^{\circ}, 45^{\circ}, 55^{\circ}, 72^{\circ}$, and $90^{\circ}$, as shown, respectively, in the $x-z$ plane on Figure 4.

To obtain a more direct comparison between the local behavior and the overall stress-strain behavior, in the following discussions we used the variables of local strain and local stress as normalized interparticle force and interparticle displacement. For this purpose, we defined a local normal stress $\sigma^{\alpha}=f_{\mathrm{n}}^{\alpha} N l / 3 \mathrm{~V}$ and a local shear stress $\tau^{\alpha}=f_{\mathrm{r}}^{\alpha} N l / 3 V$, where $l$ is the branch length and 

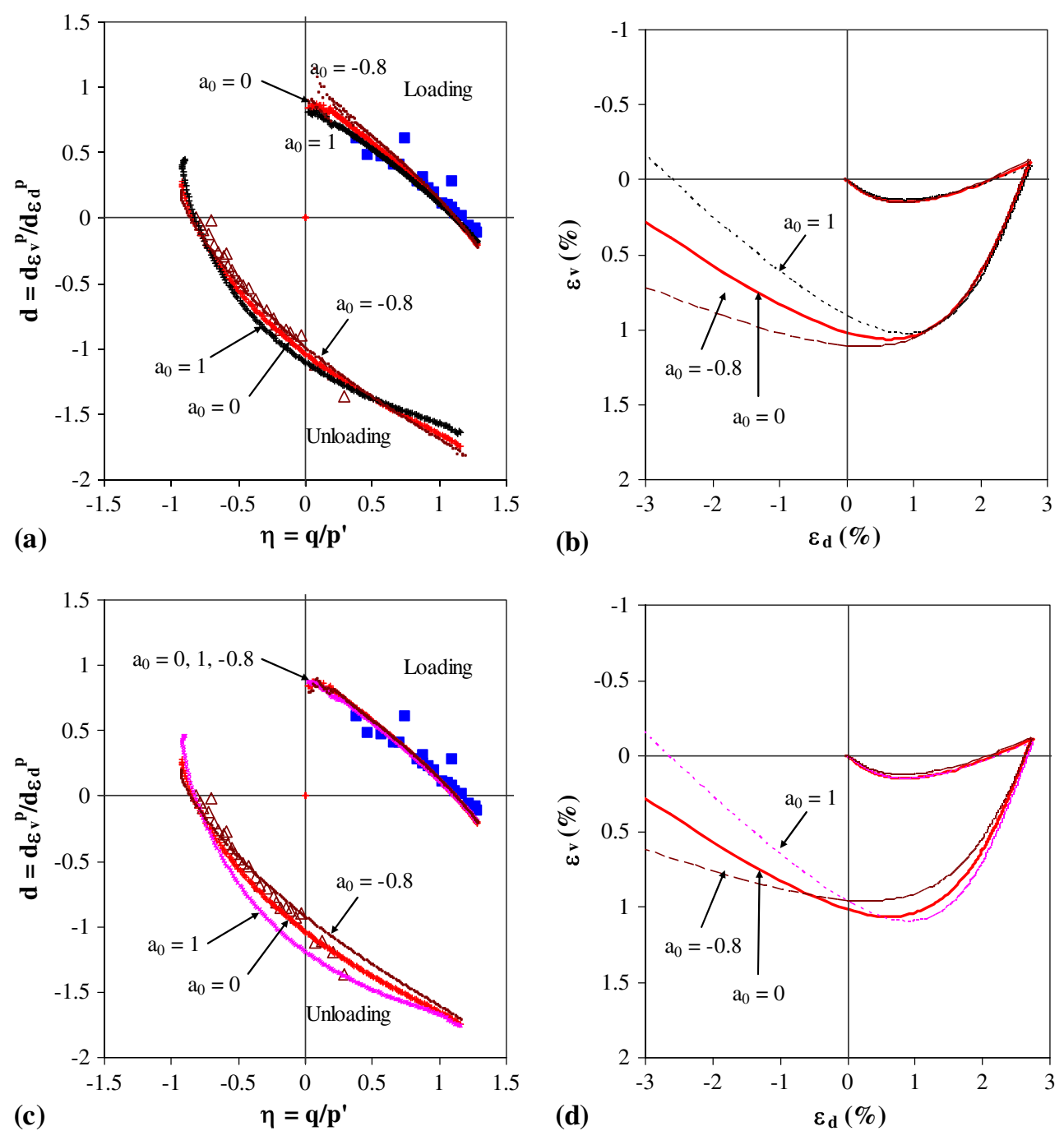

Figure 8. Comparison between experimental results and simulations for drained triaxial tests under constant $p^{\prime}=98 \mathrm{kPa}$ with loading and unloading stages.

$N / V$ is the total number of contact per unit volume. The corresponding local normal strain is defined as $\varepsilon^{\alpha}=\delta_{\mathrm{n}}^{\alpha} / l$ and a local shear strain is defined as $\gamma^{\alpha}=\delta_{\mathrm{r}}^{\alpha} / l$. With these definitions, applying static hypothesis for an isotropic material, the local stress and overall stress are related by $\tau_{i}=\sigma_{i j} n_{j}$, and the local strain and overall strain are related by $\gamma_{i}=\varepsilon_{i j} n_{j}$.

The local stress paths for the seven selected contact orientations during loading and unloading are plotted in Figures 9(a) and 9(b), respectively. The mobilized shear stresses on contact planes are different for each orientation. The $55^{\circ}$ contact planes reach the highest mobilized ratio $\tau / \sigma$ in loading condition (close to $\pi / 4+\phi_{\mathrm{m}} / 2=62.5^{\circ}$ ); the $28^{\circ}$ contact planes reach the highest ratio $\tau / \sigma$ in unloading (close to $\pi / 4-\phi_{\mathrm{m}} / 2=27.5^{\circ}$ ). For the $0^{\circ}$ and $90^{\circ}$ contact planes, shear stresses are null.

Figure 10 shows local dilatancy relations (expressed by the local normal to shear plastic strain increment $\Delta \varepsilon^{p} / \Delta \gamma^{p}$ versus shear stress to normal stress $\left.\tau / \sigma\right)$. Three different cases $\left(a_{0}=0,1\right.$ and -0.8 with $\left.D_{\text {ave }}=0.7\right)$ are plotted: Figures $10(\mathrm{a} 1)-10(\mathrm{e} 1)$ for $a_{0}=0$, Figures $10(\mathrm{a} 2)-10(\mathrm{e} 2)$ for $a_{0}=1$, and Figures 10(a3)-10(e3) for $a_{0}=-0.8$.

For the isotropic case with $a_{0}=0$ (see Figures 10(a1)-10(e1)), according to the local dilatancy used (Equation (15), the local dilatancy rate $\Delta \varepsilon^{\mathrm{P}} / \Delta \gamma^{\mathrm{p}}$ starts from $\tan \phi_{0}=0.333$ with a slope of -0.7 during 

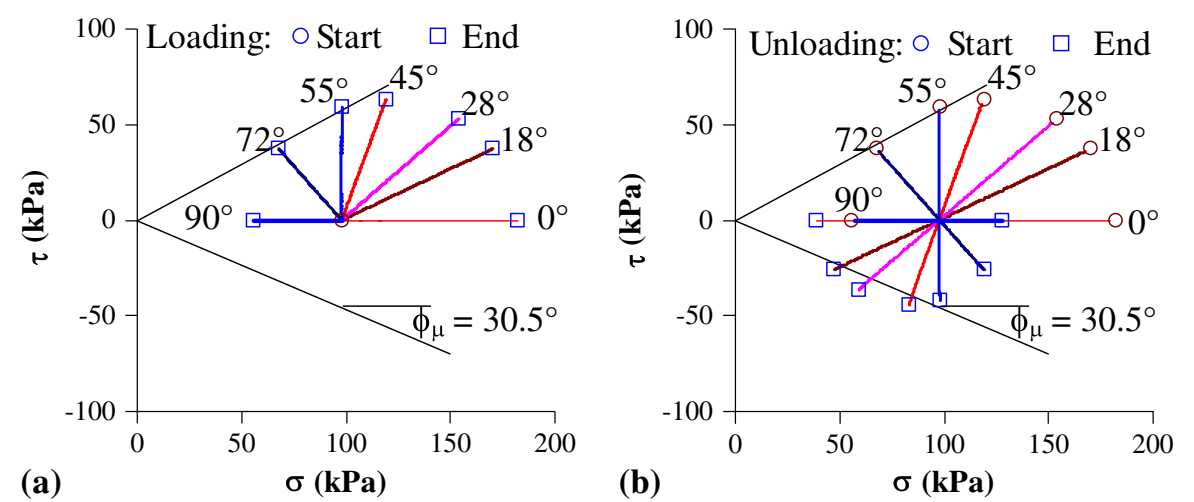

Figure 9. Local stress paths for selected plane contact orientations for (a) loading and (b) unloading stages.
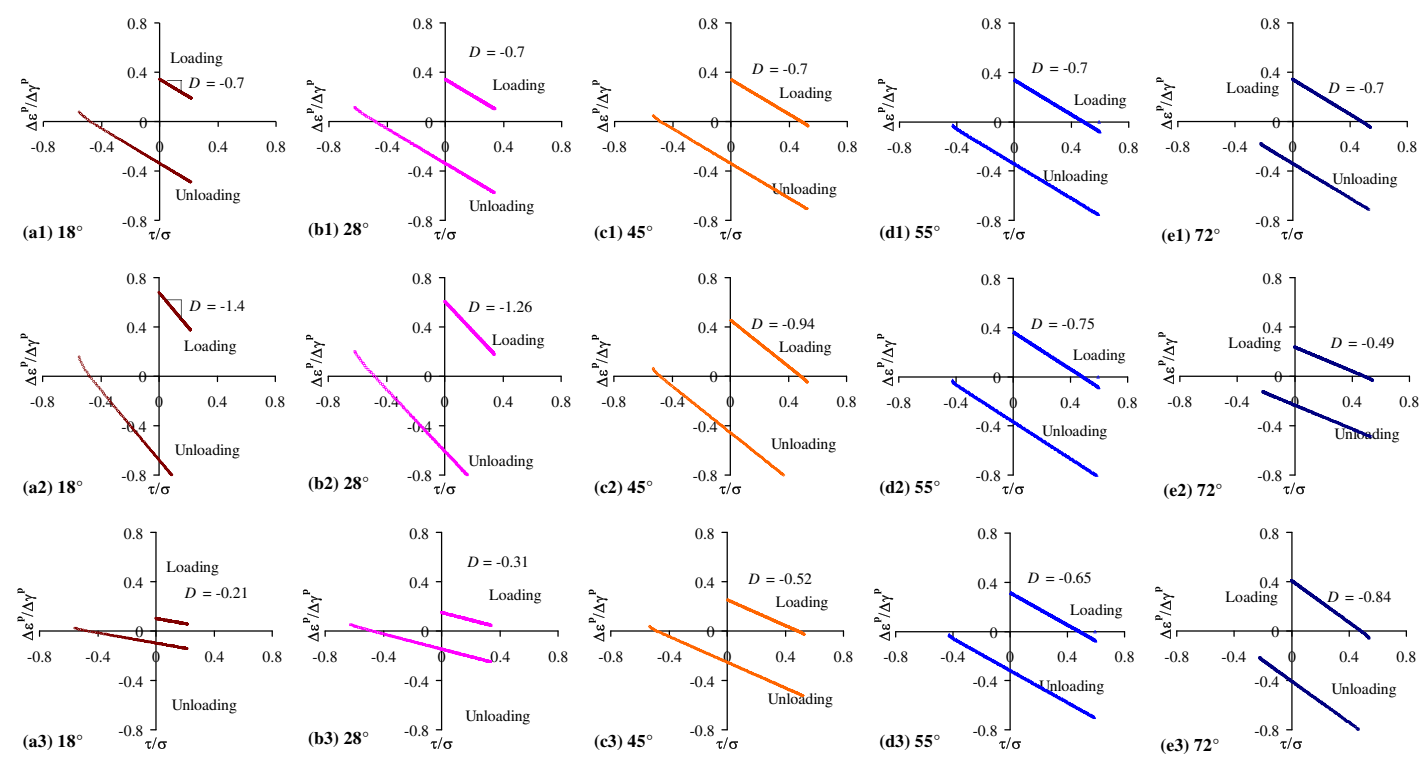

Figure 10. Local stress-dilatancy relations for selected plane contact orientations for loading and unloading stages: (a1)-(e1) $a_{0}=0$, (a2)-(e2) $a_{0}=1$, and (a3)-(e3) $a_{0}=-0.8$.

loading for all contact planes. At the end of loading stage, different planes mobilized to different ratios $\tau / \sigma$. Subsequently, at the beginning of unloading, the local dilatancy rate at different planes starts from different values but with same slope of -0.7 . For loading test, the contact planes $18^{\circ}$ and $28^{\circ}$ behave only on contraction; other planes mobilized to higher stress level and reach the dilation region. For unloading test, the contact planes $55^{\circ}$ and $72^{\circ}$ behave only on contraction and other planes behave on contraction followed by dilation.

For the anisotropic case with $a_{0}=1$ (see Figures 10(a2)-10(e2)), the contact planes with lower $\theta$ have higher local dilatancy rates and higher slopes $D$ during loading. Inverse situation can be observed for the case $a_{0}=-0.8$ (see Figures 10(a3)-10(e3)). For a given contact plane, the slopes of dilatancy curve $D$ are same under loading and unloading.

\section{2.. Predictions for undrained behavior of loose Hostun sand}

In the previous sections, the present model has been evaluated by drained tests on Toyoura sand. Here, we further evaluate the model with undrained laboratory tests on loose Hostun sand by Doanh et al. [22]. All samples were prepared in an attempt to have the same initial void ratio before 
consolidation. The initial void ratio, $e_{0}$, is approximately 1.0, corresponding to a relative density $D_{\mathrm{r}}$ less than $15 \%$. The minimum and the maximum void ratios of the Hostun RF sand are $e_{\max }=1.041$ and $e_{\min }=0.648$. The sand samples were anisotropically consolidated to confining pressures $=100,200$, 300 , and $400 \mathrm{kPa}$. Then, the specimens were sheared to failure under undrained conditions in a triaxial condition in two different stress paths: (i) increase in axial load (i.e. loading condition) and (ii) decrease in axial load (i.e. unloading condition).

The critical state void ratios obtained from these undrained tests are plotted on the $\log p^{\prime}-e$ plane, as shown in Figure $11\left(K_{0}=\sigma_{a}^{\prime} / \sigma_{r}^{\prime}\right)$. Other parameters were calibrated from two undrained triaxial tests: one in loading and one in unloading condition. Anisotropy for dilatancy constant, $a_{0}=-0.64$, is obtained by fitting the stress path for undrained extension test. All parameters used for the model are summarized in Table I.

Figure 12 presents the numerical results predicted using the set of parameters given in Table I. Both predicted undrained stress paths and stress-strain curves are in agreement with the experimentally measured curves for loose Hostun sand. The dilatancy curves cannot be directly obtained from the undrained test results. However, the dilatancy relation is closely related to the shape of undrained stress paths. The predictions in Figure 12 have demonstrated that the model is capable of capturing the shape of undrained stress paths and simulating the phenomenon of 'static liquefaction', in both loading and unloading conditions.

\section{CONCLUSIONS}

It is difficult to model the stress-dilatancy behavior of sand because the behaviors are very different under loading and unloading conditions. Furthermore, inherent anisotropy has made the dilatancy behavior of sand even more complex.

A micromechanics approach by Chang and Hicher [11] is adopted for modelling the dilatancy behavior because the micromechanics approach accounts for the underlying slip mechanism between particles as well as orientation-dependent interparticle properties. Using this method, the stressdilatancy relations under both loading and unloading conditions can be predicted with the consideration of packing structural anisotropy. Drained triaxial tests on Toyoura sand and undrained triaxial tests on loose Hostun sand were simulated to evaluate the present model. Comparisons between experimental results and micromechanical analysis have demonstrated the model's capability of describing correctly the stress-dilatancy relations under both loading and unloading conditions.

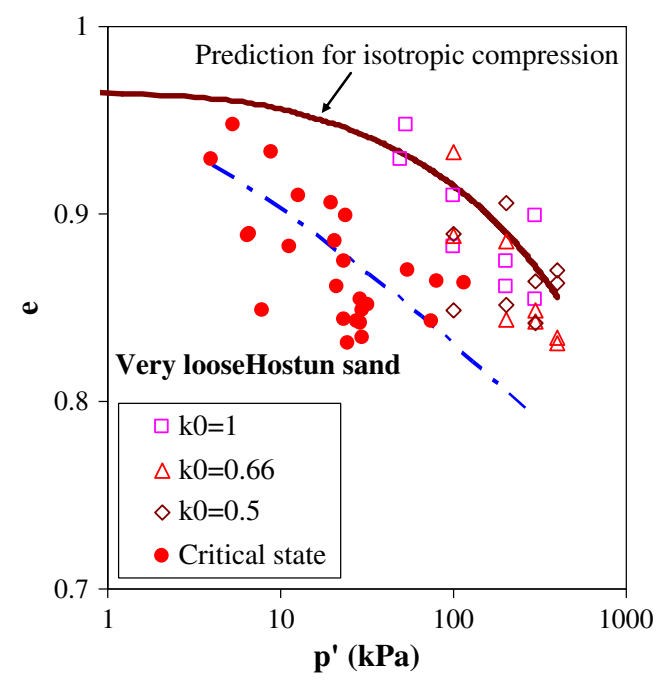

Figure 11. Critical states and isotropic compression for very loose Hostun sand. 

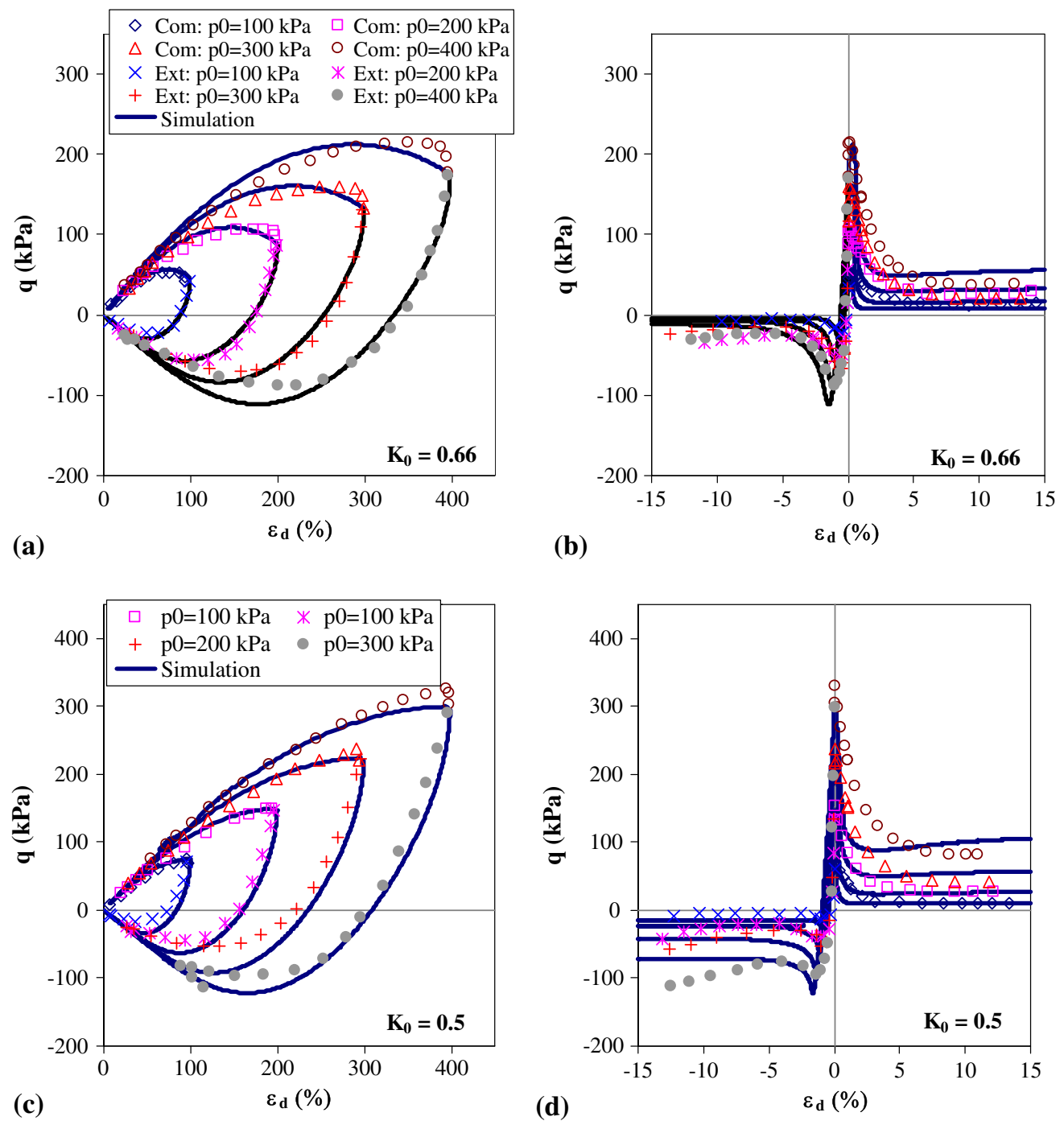

Figure 12. Comparison between experimental results and simulations for undrained triaxial tests on very loose Hostun sand under different $K_{0}$ conditions $\left(K_{0}=0.66\right.$ and 0.5$)$.

\section{APPENDIX A: MICROMECHANICAL MODEL AND DEFINITIONS OF SYMBOLS}

\section{Interparticle behavior}

The interparticle model by Chang and Hicher [11] involves the following elements: (i) elastic stiffness, (ii) friction sliding, and (iii) dilatancy. They are briefly described in the following paragraphs.

For sand grains, the elastic stiffness between two particles is given by

$$
k_{\mathrm{n}}=k_{\mathrm{n} 0}\left(\frac{f_{\mathrm{n}}}{f_{\mathrm{ref}}}\right)^{n} ; \quad k_{\mathrm{r}}-=k_{\mathrm{rR}} k_{\mathrm{n} 0}\left(\frac{f_{\mathrm{n}}}{f_{\mathrm{ref}}}\right)^{n}
$$

where $f_{\text {ref }}$ is the reference value by $f_{\text {ref }}=\frac{3 V}{N l} p_{\text {at }}$ ( $p_{\text {at }}$ is the atmosphere pressure equal to $101.3 \mathrm{kPa}$, and $V / N$ is the total number of contacts per unit volume), $f_{\mathrm{n}}$ is the contact force in normal direction, $l$ is the branch length between two particles, and $k_{\mathrm{n} 0}, k_{\mathrm{rR}}$, and $n$ are material constants. For two spherical particles, the branch length is same as particle size $l=d$. The value of $n$ is typically 0.5 for sand. 
The yield function $F$ is assumed to be of Mohr-Coulomb type, defined in a contact-force space (e.g. $f_{\mathrm{n}}, f_{\mathrm{s}}$, and $f_{\mathrm{t}}$ ),

$$
F=\frac{f_{\mathrm{r}}}{f_{\mathrm{n}}}-\kappa\left(\delta_{\mathrm{r}}^{\mathrm{p}}\right)
$$

where $\kappa\left(\delta_{r}^{P}\right)$ is a hardening function. When $\mathrm{d} F>0$, it indicates loading, otherwise unloading.

Note that the shear force $f_{\mathrm{r}}$ and the plastic sliding $\delta_{\mathrm{r}}^{\mathrm{P}}$ can be defined as

$$
f_{\mathrm{r}}=\sqrt{f_{\mathrm{s}}^{2}+f_{\mathrm{t}}^{2}} \text { and } \delta_{\mathrm{r}}^{\mathrm{p}}=\sqrt{\left(\delta_{\mathrm{s}}^{\mathrm{p}}\right)^{2}+\left(\delta_{\mathrm{t}}^{\mathrm{p}}\right)^{2}}
$$

The hardening function is defined by a hyperbolic curve in $\kappa-\delta_{\mathrm{r}}^{\mathrm{p}}$ plane, which involves two material constants: $\phi_{\mathrm{p}}$ and $k_{\mathrm{p}}$.

$$
\kappa=\frac{k_{\mathrm{p}} \tan \phi_{\mathrm{p}} \delta_{\mathrm{r}}^{\mathrm{p}}}{\tan \phi_{\mathrm{p}}+k_{\mathrm{p}} \delta_{\mathrm{r}}^{\mathrm{p}}}
$$

The value of $\kappa$ asymptotically approaches the apparent interparticle friction angle $\tan \phi_{p}$. The initial slope of the hyperbolic curve, $k_{\mathrm{p}}$, is assumed to relate $k_{\mathrm{n}}$ by a constant $k_{\mathrm{pR}}$ :

$$
k_{\mathrm{p}}=k_{\mathrm{pR}} k_{\mathrm{n}} / f_{\mathrm{n}}
$$

The elastic sliding behavior between two particles does not have a shear induced normal movements. However, the plastic sliding often occurs along the contact plane with an upward or downward movement, which is the shear-induced dilation/contraction. It is postulated that

$$
\frac{d \delta_{\mathrm{n}}^{\mathrm{p}}}{d \delta_{\mathrm{r}}^{\mathrm{p}}}=D\left(\tan \phi_{0}-\frac{f_{\mathrm{r}}}{f_{\mathrm{n}}}\right)
$$

where $D$ is material constant for local dilatancy. The $\tan \phi_{0}$ represents the obliquity at which the plastic normal movement is zero, which is related to the phase transformation line of the soil assembly.

With the elastic and plastic behavior previously described, the final incremental force-displacement relationship of the interparticle contact can be derived, given by

$$
\dot{f}_{i}^{\alpha}=k_{i j}^{\alpha} \dot{\delta}_{j}^{\alpha}
$$

A detailed expression of the elastoplastic stiffness tensor can be derived from yield function and flow rule (see Chang and Hicher [11]), in which $k_{i j}^{\alpha}$ is the function of $k_{\mathrm{n} 0}, k_{\mathrm{rR}}, k_{\mathrm{pR}}, \tan \phi_{\mathrm{p}}, D$, and $f_{\mathrm{r}} / f_{\mathrm{n}}$. The derivation is not included here.

\section{Influence of density state}

To account for the interactions among neighbouring particles, we introduced a density state $\psi=e_{c} / e$ in reference to the void ratio at critical state.

Soil is said to be in critical state when it undergoes large shear deformations at a constant volume and a constant stress state. The void ratio corresponding to this state is $e_{c}$. The critical state line can be expressed as follows for sand: 


$$
e_{\mathrm{c}}=e_{\mathrm{ref}}-\lambda\left(\frac{p^{\prime}}{p_{\mathrm{at}}}\right)^{\xi}
$$

where $\xi$ and $\lambda$ are two material constants, and $p^{\prime}$ is the mean effective stress of the packing.

Resistance against sliding on a contact plane is dependent on the degree of interlocking by neighboring particles. The resistance can be related to the state of packing void ratio $e$ by

$$
\tan \phi_{\mathrm{p}}=\left(\frac{e_{\mathrm{c}}}{e}\right)^{m} \tan \phi_{\mu}
$$

where $m$ is a material constant, which is typically equal to 1 . For dense packing, the apparent interparticle friction angle $\phi_{\mathrm{p}}$ is greater than the internal friction angle $\phi_{\mu}$. When the packing structure dilates, the degree of interlocking and the apparent frictional angle are reduced, which results in a strain-softening phenomenon. For loose packing, the apparent frictional angle $\phi_{p}$ is smaller than the internal friction angle $\phi_{\mu}$.

\section{Overall stress-strain relationship}

The stress-strain relationship for an assembly can be determined from integrating the behavior of interparticle contacts in all orientations. In the integration process, a micro-macro relationship is required. Using the static hypothesis, we obtain the relation between the global strain and the interparticle displacement,

$$
\dot{u}_{j, i}=A_{i k}^{-1} \sum_{\alpha=1}^{N} \dot{\delta}_{j}^{\alpha} l_{k}^{\alpha} ; \quad A_{i k}=\sum_{\alpha=1}^{N} l_{i}^{\alpha} l_{k}^{\alpha}
$$

where the branch vector $l_{k}^{\alpha}$ is defined as the vector joining the centers of two particles, and $A_{i j}$ is the fabric tensor. Using this hypothesis, the mean force on the contact plane of a given orientation $\alpha$ is

$$
\dot{f}_{j}^{\alpha}=\dot{\sigma}_{i j} A_{i k}^{-1} l_{k}^{\alpha V}
$$

The stress increment can be obtained by the contact forces and branch vectors for all contacts as follows:

$$
\dot{\sigma}_{i j}=\frac{1}{V} \sum_{\alpha=1}^{N} \dot{f}_{j}^{\alpha} l_{i}^{\alpha}
$$

Apply Equation (A12) to the stress in Equation (A11), it can be observe that Equation (A11) is satisfied automatically.

Using Equations (A10), (A7), and (A11), the following relationship between stress increment and strain increment can be obtained:

$$
\dot{u}_{i, j}=C_{i j m p} \dot{\sigma}_{m p} ; \quad \text { where } \quad C_{i j m p}=A_{i k}^{-1} A_{m n}^{-1} V \sum_{\alpha=1}^{N}\left(k_{j p}^{e p}\right)^{-1} l_{k}^{\alpha} l_{n}^{\alpha}
$$

When the contact number $N$ is sufficiently large in an isotropic packing, the summation of flexibility tensor in Equation (A13) and the summation of fabric tensor in Equation (A10) can be written in integral form, given by 


$$
\begin{gathered}
C_{i j m p}=A_{i k}^{-1} A_{m n}^{-1} \frac{N V}{2 \pi} \int_{0}^{\pi / 2} \int_{0}^{2 \pi} k_{j p}^{e p}(\theta, \beta)^{-1} l_{k}(\theta, \beta) l_{n}(\theta, \beta) \sin \theta d \theta d \beta ; \text { and } \\
A_{i k}=\frac{N}{2 \pi} \int_{0}^{\pi / 2} \int_{0}^{2 \pi} l_{i}(\theta, \beta) l_{k}(\theta, \beta) \sin \theta d \theta d \beta
\end{gathered}
$$

The integration of Equations (A14) and (A15) in a spherical coordinate can be carried out numerically using Gauss integration points over the surface of the sphere.

\section{ACKNOWLEDGEMENT}

The authors thank the Pujiang Talent People Plan of Shanghai (11PJ1405700). Zhen-Yu Yin was formerly a research fellow at the Research Institute in Civil and Mechanical Engineering, UMR CNRS 6183, Ecole Centrale de Nantes.

\section{REFERENCES}

1. Rowe PW. The stress-dilatancy relations for static equilibrium of an assembly of particles in contact. Proceedings of the Royal Society of London Series A 1962; 269:500-527.

2. Roscoe KH, Schofield AN, Thurairajah A. Yielding of clays in states wetter than critical. Geotechnique 1963; 13(3):211-240.

3. Nova R. A constitutive model for soil under monotonic and cyclic loading. In Soil echanics transient and cyclic loads, Pande GN, Zienkiewicz OC (eds.). Wiley: Chichester, 1982; 343-373.

4. Jefferies MG. Plastic work and isotropic softening in unloading. Geotechnique 1997; 47(5):1037-1042.

5. Manzari MT, Dafalias YF. A critical state two-surface plasticity model for sands. Geotechnique 1997; 47(2): 255-272.

6. Gajo A, Muir Wood D. Severn-Trent sand: a kinematic hardening constitutive model: the q-p formulation. International Journal for Numerical and Analytical Methods in Geomechanics 1999; 23(9):925-965.

7. Li XS, Dafalias YF, Wang ZL. State-dependent dilatancy in critical-state constitutive modeling of sand. Canadian Geotechnical Journal 1999; 36(4):599-611.

8. Wan RG, Guo PJ. Drained cyclic behaviour of sand with fabric dependence. Journal of Engineering Mechanics 2001; 127(11):1106-1116.

9. Anandarajah A. Modeling liquefaction by a multimechanism model. Journal of Geotechnical and Geoenvironmental Engineering 2008; 134(7):949-959.

10. Pradhan TBS, Tatsuoka F. On stress-dilatancy equations of sand subjected to cyclic loading. Soils and Foundations 1989; 29(1):65-81.

11. Chang CS, Hicher PY. An elastic-plastic model for granular materials with microstructural consideration. International Journal of Solids and Structures 2005; 42(14):4258-4277.

12. Taylor DW. Fundamentals of soil mechanics. J. Wiley and Sons: NewYork, 1948.

13. Ishihara K, Towhata I. Cyclic behaviour of sand during rotation of principal axes. Mechanics of Granular Materials, Ed. Elsevier, 1983; 55-73.

14. Luong MP. stress-strain aspects of cohesionless soils under cyclic and transient loading. Int. Symp. on Soils under Cyclic and Transient Loading, Swansea, 1980; 353-376.

15. Rowe PW. The relation between the shear strength of sand in triaxial compression, plane strain and direct shear. Geotechnique 1969; 19(1):75-86.

16. Pradhan TBS, Tatsuoka F, Sato Y. Experimental stress-dilatancy relations of sand subjected to cyclic loading. Soils and Foundations 1989; 29(1):45-64.

17. Jefferies M, Been K. Soil liquefaction: A critical state approach. Taylor \& Francis: Milton Park, Abingdon, Oxon, UK, 2006.

18. Yu H-S, Khong C, Wang J. A unified plasticity model for cyclic behaviour of clay and sand. Mechanics Research Communications 2007; 34(2):97-114.

19. Biarez J, Hicher PY. Elementary Mechanics of Soil Behaviour. Balkema: Rotterdam, The Netherlands, 1994; 208.

20. Verdugo R, Ishihara K. The steady state of sandy soils. Soils and Foundations 1996; 36(2):81-91.

21. Chang CS, Misra A. Application of uniform strain theory to heterogeneous granular solids. ASCE Journal of Engineering Mechanics 1990; 116(10):2310-2328.

22. Doanh T, Ibraim E, Matiotti R. Undrained instability of very loose Hostun sand in triaxial compression and extension. Part 1: Experimental observations. Mechanics of Cohesive-Frictional Materials 1997; 2(1):47-70. 